\title{
A nova gestão pública: alguns impactos nas políticas educacionais e na formação de professores
}

\author{
The new public management: some impacts on \\ educational policy and teacher training \\ La nueva gestión publica: algunos impactos en las \\ políticas educacionales y en la formación de profesores
}

MARIA DE FÁtIMA CóSSIO*

\begin{abstract}
$\longrightarrow \diamond \stackrel{ }{\longrightarrow}$
RESUMO

Este artigo visa a analisar o contexto em que emergem as políticas educacionais, sobretudo aquelas voltadas à formação de professores. Defende-se a tese de que as reformas educacionais dos últimos anos, asseveradas recentemente, fazem parte das transformações do papel do Estado, em que se situa a Nova Gestão Pública (NGP) e o atual modelo de globalização neoliberal. Com vistas à modernização da gestão pública, superando a administração burocrática, considerada ineficiente, a NGP implica, entre outros fatores, introduzir na máquina pública princípios e práticas do setor privado (gerencialismo). Ao mesmo tempo em que propõe as parcerias com outros setores/entes para a execução de ações antes exclusivas do Estado (governança). O argumento é que o Estado, entendido como monolítico e centralizado, também não atende aos desafios da sociedade. Esse cenário se torna adequado à nova privatização na/da educação (princípios privados no setor público) em todos os níveis e etapas da educação.

Palavras-chave: Nova Gestão Pública. Governança. Políticas educacionais. Formação de professores.
\end{abstract}

\begin{abstract}
This article aims to analyze the context in which educational policies emerge, especially those focused on teacher education. The thesis is defended that the educational reforms of recent years, recently affirmed, are part of the transformations of the role of the State, in which the New Public Management - NGP and the current model of neoliberal globalization stand. With a view to the modernization of public management, overcoming bureaucratic administration, seen as inefficient, the NGP has implied, among other factors, to introduce into the public machine principles and practices of the private sector (Managerial), at the same time, under the argument that the State, understood as monolithic and centralized also does not meet the challenges of society, proposes partnerships with other sectors/entities to carry out actions previously exclusive to the State (Governance). This scenario becomes appropriate to the new privatization in education (private principles in the public sector) at all levels and stages of education.
\end{abstract}

Keywords: New Public Management. Governance. Educational policies. Teacher training.

\section{RESUMEN}

Este artículo busca analizar el contexto en que emergen las políticas educativas, sobre todo aquellas orientadas a la formación de profesores. Se defiende la tesis de que las reformas educativas de los últimos años, aseveradas recientemente, forman parte de las transformaciones del papel del Estado, en que se sitúa la Nueva Gestión Pública - NGP y el actual modelo de globalización neoliberal. En cuanto a la modernización de la gestión pública, superando la administración burocrática, vista como ineficiente, la NGP ha implicado, entre otros factores, en introducir en la máquina pública principios y prácticas del sector privado (Gerencialismo), al mismo tiempo que, bajo el argumento de que el Estado, entendido como monolítico y centralizado tampoco atiende a los desafíos de la sociedad, propone las alianzas con otros sectores / entes para la ejecución de acciones antes exclusivas del Estado (Gobernanza). Este escenario se vuelve adecuado para la nueva privatización en la educación (principios privados en el sector público), en todos los niveles y etapas de la educación.

Palabras clave: Nueva Gestión Pública. Gobernanza. Políticas educativas. Formación de profesores.

\footnotetext{
* Doutora em Educação (UFRGS) e Pós-doutora em Educação pela UFSC. Líder do Núcleo de Estudos e Pesquisas em Políticas Educacionais - NEPPE.

Pró-Reitora de Ensino na Universidade Federal de Pelotas. Universidade Federal de Pelotas - PPGEDU. E-mail: cossiofatima13@gmail.com
} 


\section{INTRODUÇÃO}

O setor público tem passado nos últimos anos por uma reforma estrutural que vem alterando de forma significativa as concepções e os objetivos que orientam as formas de gestão e o funcionamento das instituições. Essas reformas administrativas consolidam novos discursos e práticas derivadas do setor privado e são usadas como referência para organizações públicas em todas as esferas de governo.

De acordo com Secchi (2009), dois modelos organizacionais e um paradigma relacional foram apresentados como alternativas ao modelo de administração burocrática do setor público. A administração pública gerencial (AGP) e o governo empreendedor (GE) são modelos organizacionais que incorporam prescrições para a melhora da efetividade da gestão das organizações públicas. O movimento da governança pública (GP) se traduz em um modelo relacional porque oferece uma abordagem diferenciada de conexão entre o sistema governamental e o ambiente que circunda o governo.

Tais modelos, também chamados de pós-burocráticos (MAROY, 2011, BALL, 2001, 2005), ou Nova Gestão Pública (NGP), passam a ser utilizados como elementoschave para a efetivação dos conceitos neoliberais, buscando, assim, paralelamente, a iniciativa de liberar as forças do mercado e reduzir o tamanho e as ações do Estado, aumentar a eficiência do setor público e reduzir o seu custo.

De acordo com Dasso Júnior (2015), Michel Messenet, na obra La Nouvelle Gestion Publique: pour un etat sans burocratie, publicada em 1975, foi quem primeiro cunhou a expressão Nova Gestão Pública (NGP) ao criticar a administração pública burocrática. Entretanto, foi Christopher Hood, no artigo A public management for all seasons?, publicado em 1991, quem a apresentou como conceito para nominar a teoria de administração pública que se impunha. Segundo Hood (1996), a ideologia da NGP ganhou popularização em 1992, com o lançamento do livro Reinventing government, de David Osborne e Ted Gaebler.

A NGP situa-se, segundo Dasso Júnior (2015), em um primeiro momento, no cenário das transformações no papel do Estado voltadas ao ajuste estrutural das economias em crise, sobretudo nos países centrais, no final da década de 1970 (ajuste fiscal, privatização, liberalização do comércio, alterações no modo de produção), e à supremacia do princípio do mercado com a inserção do modelo neoliberal. E, em um segundo momento, nos anos 1990, a ênfase da NGP recai nas transformações de caráter institucional (competitividade, concorrência, avaliação por resultados, meritocracia, planejamento estratégico, eficiência, eficácia), especialmente com o enfoque da participação da sociedade civil. Assim, o contexto da NGP comporta e promove uma forma de gestão que, entre outras medidas, adota a celebração de parcerias público-privadas (PPPs) enquanto configuração das políticas públicas, entre as quais inserem-se as de educação.

A partir dessa configuração e redesenho da gestão pública, no quadro das transformações no papel do Estado, situam-se as políticas para a educação superior e, mais especificamente, as políticas para a formação de professores. Busca-se neste artigo analisar algumas relações do contexto mais amplo com o momento atual em que a reforma educacional se produz e sinalizar para alguns impactos sobre a formação de professores e sobre o trabalho docente.

Para tanto, o texto está organizado em três seções. A primeira trata da Nova Gestão Pública (NGP), no quadro das transformações do papel do Estado e da governança. A segunda seção discute algumas políticas que orientam a educação superior no Brasil, buscando destacar os impactos na formação de professores, no contexto da governança educacional. Por fim, a última seção pretende aproximar o movimento da reforma educacional com a reconfiguração da gestão pública.

\section{NOVA GESTÃo PÚBLICA (NGP) E AS TRANSFORMAÇÕES NO PAPEL DO ESTADO}

Embora ao termo "gestão" possam ser atribuídos diferentes significados, assume-se a concepção de que representa um ato complexo que se refere ao mundo da política e que gerir o setor público é diferente de gerir o setor privado.

Nessa tônica, a gestão pública pressupõe escolhas e expressão de valores sociais e políticos, e não apenas instrumentais. Dentro da lógica política, a gestão pública deve facilitar a expressão de vontades, realizar a mediação entre estas e encontrar valores para conduzir as ações (CARNEIRO; MENICUCCI, 2013). Assim, analisar a gestão pública é analisar o Estado e sua configuração, o que remete ao papel por este assumido historicamente, em diferentes contextos. No momento atual, implica buscar compreender as suas transformações como parte da reorientação do modelo de globalização neoliberal.

O movimento reformista desencadeado com a prevalência do modelo neoliberal se desdobra em dois eixos centrais: o primeiro se refere à redução do alcance do governo e à permeabilidade à inserção de outros atores na definição/ação de políticas públicas; e o segundo diz respeito às mudanças no interior da administração pública, visando a sua modernização e eficiência aos moldes das empresas privadas, configurando a NGP. 
No primeiro eixo, que prevê a redução do tamanho do Estado, destacam-se dois movimentos. O primeiro é o da privatização stricto sensu, pois procura retirar da alçada do Estado e transferir para a órbita do mercado tudo aquilo que pode ser retirado, com destaque para a produção de mercadorias. Em simultâneo, o segundo movimento apresenta um esforço de reorganizar a forma de funcionamento das atividades fins que se mantêm sob a responsabilidade do Estado, incluindo diferentes arranjos entre organizações públicas e privadas. Como também envolve a proliferação de formas híbridas de organização, como as denominadas PPPs, nas quais reside a permeabilidade do Estado.

A reforma gerencial visa a adotar no setor público o modelo organizacional e de gestão utilizado pelas grandes corporações da iniciativa privada, ou seja, busca inserir na raiz do sistema público conceitos e práticas voltados a eficiência, eficácia, competitividade, administração por objetivos, meritocracia e demais concepções oriundas de um meio em que a finalidade é a obtenção de lucro e que, portanto, dispensa pouca atenção para as finalidades sociais.

O Governo Empreendedor (GE) é complementar à perspectiva gerencial, cujas ideias foram utilizadas com maior intensidade nos Estados Unidos, nas eleições presidenciais de 1992 (SECCHI, 2009). O autor destaca as prescrições de Osborne e Gaebler (1992), que sintetizaram em uma lista de 10 mandamentos a receita para transformar uma organização pública burocrática em uma organização pública racional e eficaz.

Esse movimento de governança pública (GP) emerge no contexto da implementação das políticas neoliberais em oposição ao termo governo que está fortemente marcado pelo adjetivo estatal (OLIVEIRA, 2011).

A sociedade civil, nessa perspectiva, assume um papel central, tanto para realizar os serviços entendidos como "não exclusivos do Estado" quanto para legitimar o modelo através do controle a distância (avaliações, conselhos, agências reguladoras) das ações realizadas, dando a ideia de transparência e controle social.

Pode-se dizer que o termo governança, do inglês governance, surge no contexto da reforma do Estado e na esteira da NGP, indicando novas formas de ação política (SHIROMA, 2016).

De acordo com Reis (2013), foi Ronald Coase quem, num artigo intitulado The nature of the firm, em 1937, tratou pela primeira vez do termo governance, referindose aos dispositivos adotados pelas empresas para reduzir os custos de transação, resultantes da coordenação econômica. Mas é em 1975 que esse conceito se formaliza com o trabalho do economista americano Oliver E. Williamson: Markets and hierarchies: analysis and antitrust implications. A partir de então, o conceito de governance difunde-se, mas também se diferencia de outros termos similares, no âmbito das análises econômicas, dirigindo-se à problemática da coordenação.

Reis (2013, p. 106) afirma;

Governança pode traduzir-se pelo modo de coordenação dos diferentes tipos de arranjos institucionais presentes num dado sistema social de produção, Mercados, Hierarquias, Estado, Redes, Associações e Comunidades, cujas ordens relacionais, diversas e parciais, configuram uma dada forma institucional dominante ou prevalecente.

Governança não é sinônimo de governabilidade, nem tem como objeto de estudo a arquitetura institucional de um dado sistema jurídico-político. O seu significado é mais aberto e distintivo, na medida em que se refere à análise dos padrões de articulação e cooperação entre os atores e os arranjos institucionais que coordenam os sistemas sociais.

A autora destaca que é possível encontrar nove modelos de governança em que se cruzam diferentes disciplinas, com abordagens metodológicas e analíticas distintas. No primeiro grupo, destaca:

a (i) good governance, (ii) good governance - nova gestão pública e (iii) governança empresarial. Neste caso, o termo governança, quer como paradigma científico, quer como referencial político, afirma-se nos anos de 1990, surgindo como um potente motor de reformas ao nível de métodos de decisão e de ação coletiva que tem em conta a evolução do papel do Estado. Face aos processos de 'globalização', à emergência de novas categorias de atores (diversas organizações mundiais) e à integração económica de várias zonas e regiões do globo, impõe-se uma redefinição do lugar e do papel do Estado, cujas configurações possíveis confrontam a sua legitimidade e o seu tradicional princípio de soberania (REIS, 2013, p. 13).

Shiroma (2016,p. 76) afirma que o termo governança é utilizado em várias áreas - ciência política, administração, economia e sociologia, relações internacionais, entre outras - e cita Vasconcellos (2011):

No setor público, a utilização do conceito tem servido para legitimar as políticas neoliberais e os processos de desestatização. Os actores políticos têm-no utilizado num sentido normativo de modo a legitimar a realização de reformas na administração pública ou nas estruturas políticas institucionais, como no caso do debate acerca da 'nova gestão pública' (Rhodes, 2000), ou ainda no discurso e nas práticas da 'boa governança' utilizada nas agências internacionais, como, por exemplo, o Banco Mundial. No caso do sector privado, a ênfase centra-se na 'boa governança corporativa', segundo a 
qual 'o mundo dos negócios deveria arcar com maiores responsabilidades, por exemplo, na área dos direitos dos consumidores e da protecção do ambiente'. No caso do terceiro sector, para legitimar e defender as actividades sem fins lucrativos que complementam a acção do Estado (VASCONCELOS, 2011, p. 25).

Assim, a Nova Gestão Púbica pode ocorrer combinando o gerencialismo, o governo empreendedor e a governança, pois todos buscam tornar a gestão pública mais eficaz e mais eficiente, visando a sua modernização, o que significa, nesse ideário, corresponder às expectativas do mercado dentro da lógica das empresas privadas lucrativas.

No caso brasileiro, a reforma do Estado se materializa de forma objetiva em 1995, com o Plano Diretor da Reforma do Aparelho do Estado, produzido pelo Ministério da Administração e Reforma do Estado - Mare -, sob a gestão do ministro Bresser Pereira, no primeiro mandato do presidente Fernando Henrique Cardoso. As estratégias assinaladas pelo plano são: privatização, publicização e terceirização. Peroni (2011) destaca que o termo "publicização" consiste na transferência para o setor público não estatal dos serviços sociais e científicos tradicionalmente prestados pelo Estado. A criação da categoria "público não estatal" contempla grandes setores da iniciativa privada, sem fins lucrativos, que prestam serviços públicos, como é o caso da educação. Ainda conforme o plano, as políticas sociais são consideradas serviços não exclusivos do Estado e, portanto, de propriedade pública não estatal ou privada.

Dessa forma, sob o argumento de modernização da máquina pública, com o intuito de torná-la mais efetiva e eficaz, as instituições das diferentes esferas de governo são instadas a adotar padrões de organização e funcionamento próprios da área privada, dentre eles a noção de rentabilidade, competitividade, concorrência, desfigurando, em alguns casos, o próprio papel institucional e suas funções.

\section{GOVERNANÇA EDUCACIONAL: POLÍTICAS PARA A FORMAÇÃO DE PROFESSORES}

A reforma do Estado e seus desdobramentos são perceptíveis na educação por meio das configurações das políticas públicas para o setor. Destacam-se, de forma geral, a ênfase na gestão por resultados; currículos e práticas pedagógicas homogeneizadas (atual Base Nacional Comum Curricular) e condicionadas às avaliações em larga escala; incentivo à ampliação da performance, medidas pela produtividade (professores, alunos, gestores), tendo em vista um tipo particular de qualidade na educação que, de acordo com Peroni (2015), visa a formar um sujeito instrumental à reestruturação e também um trabalhador e consumidor adequado à expansão do capital.

Anunciada como a perspectiva a ser perseguida pelo conjunto de medidas adotadas, a qualidade educacional tem por base os diagnósticos e censos educacionais que revelam baixos índices de rendimentos, se comparados aos países desenvolvidos, como é o caso da avaliação promovida pela $\mathrm{OCDE}^{1}$. A qualidade na educação é inegavelmente desejável; entretanto, é preciso ter clareza de qual qualidade se está falando.

Educação na perspectiva democrática, referenciada socialmente, compreende a qualidade como uma concepção ligada diretamente ao desenvolvimento social dos cidadãos, garantindo que a aprendizagem escolarizada sirva como forma de emancipação humana (FREITAS, 2005). Já a concepção de qualidade na lógica empresarial está atrelada ao rendimento escolar, passível de verificação através de testes padronizados e representada por indicadores de desempenho e sistemas de ranqueamento, com a finalidade de atingir resultados satisfatórios e adequados aos padrões definidos externamente.

Nesse contexto, a reforma da educação pública vai se consolidando, pautada por um modelo de qualidade e eficiência, o qual não raramente distanciase dos princípios pedagógicos e formativos, em vista da conformação à lógica gerencial que passa a orientar as políticas educacionais.

Para Robertson (2013), essa lógica gerencial que atinge a educação pública pode ser chamada de governança educacional. Para a autora, é um termo usado para descrever atividades do governo que cada vez mais não são realizadas por este sozinho, mas também por atores não governamentais. Além disso, ressalta que a governança como conceito também se tornou uma forma de englobar as atividades de governo daquelas organizações e empresas multilaterais, transnacionais e internacionais que cada vez mais operam acima e através das fronteiras territoriais nacionais, revelando as influências destas sobre as decisões políticas locais.

Robertson (2013) salienta que as "formas atuais de privatização na e da governança educacional, e na globalização da educação como setor de serviços, estão ligadas a um projeto político comum, aquele do neoliberalismo" (p. 686-607). Dessa maneira, alerta para a necessidade de aprofundamento do que afinal está em jogo nesse paradigma de governo, na medida em que não ficam claros quais propósitos, quais espaços e quem são os atores que atuam na educação, considerando nesse campo a questão da justiça social. Mesmo que se reconheçam os limites da ideia de justiça presente na noção de "educação

\footnotetext{
Programa Internacional para a Avaliação de Alunos (Pisa)/Organização para a Cooperação e Desenvolvimento Econômico.
} 
para todos", pois tem assento na lógica distributiva e não na mudança estrutural da sociedade, é inegável o que esta representa em termos de possibilidades sociais e o que pode acarretar a sua ausência. No entanto, não se pode pensar em qualquer modelo de educação para todos, ainda mais quando a agenda educacional (princípios, propostas, currículos, etc) está se distanciando dos propósitos caros à educação pública.

O que se observa atualmente é que, diferentemente do que ocorreu nos anos 1990, sobretudo durante os governos do presidente Fernando Henrique Cardoso, em que a proposta de privatização, na esteira da Reforma do Estado, estava mais evidente, não há um movimento de transferência direta da responsabilidade com a educação da esfera pública para a privada. Porém, no quadro da nova gestão pública, sob os auspícios da "governança", há forte atuação de parceiros, com destaque ao empresariado, sob diferentes formas e modalidades.

Robertson (2013) argumenta que é uma nova forma de privatização, pois entende que a "privatização não aparece somente com uma forma, ou mesmo totalmente formada. Suas formas diferentes também mudam com o tempo e em relação a contextos específicos” (p. 687).

A ideia de privatização na e da educação também é compartilhada por Ball (2014), quando expressa que "as mudanças endógenas em organizações do setor público tornam possível, ou seja, estabelecem as bases para a substituição exógena - a privatização -, em diferentes formas, de serviços da educação pública" (p. 64).

As políticas para a educação superior, sobretudo as que se referem às instituições públicas, considerando o atual nível de contingenciamento dos recursos destinados ao sistema federal, estão sendo, cada vez mais, orientadas pela lógica privatizante. $\mathrm{O}$ que envolve a gestão dos recursos, alguns deles condicionados aos resultados (aumento do número de alunos por turma, ampliação dos turnos de oferta dos cursos, relação entre concluintes e ingressantes), além da ênfase na avaliação dos estudantes - Enade -, reconhecimento e renovação de reconhecimento, avaliação institucional, como mecanismos de ranqueamento institucional.

O controle sobre as IES públicas, sob a alegação de transparência e prestação de contas à sociedade, tem produzido por parte do governo e de outros agentes públicos um cenário, fortemente reiterado pela mídia, de descrédito em relação à gestão de recursos e formas de administração, sendo que recentemente algumas universidades, de reconhecida competência e relevância social, estão sendo alvo de investigações, com impactos desastrosos para as comunidades acadêmicas locais e para a educação nacional.

Soma-se a isso o resultado de relatório recente apresentado pelo Banco Mundial: "Um Ajuste Justo: análise da eficiência e equidade do gasto público no Brasil" (BANCO MUNDIAL, 2017). Este, em um de seus capítulos, trata da educação brasileira e, em especial, do seu financiamento. O título do capítulo é: "Gastar mais ou melhor? Eficiência e equidade da educação pública".

Dentre outras questões, o relatório afirma que os gastos públicos com a educação superior são ineficientes e cerca de $50 \%$ poderiam ser economizados; que os gastos com educação no Brasil equivalem a $6 \%$ do PIB e que em 2010 o valor era superior à média dos países da OCDE, sem considerar o valor aplicado por matrícula; que o gasto com alunos nas instituições públicas federais é duas ou três vezes maior do que nas instituições privadas, sem fazer a distinção entre o "custo" e "gasto"; que o aumento dos gastos com educação não corresponde ao aumento do desempenho (resultados educacionais); que há um elevado índice de reprovação e evasão apesar das baixas e decrescentes razões professor-aluno, sem justificar quais fontes foram utilizadas para fundamentar tal afirmativa. Por fim, o relatório, em sua página 131, apresenta a seguinte afirmação:

\begin{abstract}
'A pequena minoria de estudantes que frequentam universidades públicas no Brasil tende a ser de familias mais ricas que frequentaram escolas primárias $\mathrm{e}$ secundárias privadas'. Primeiramente há uma imprecisão desnecessária na linguagem ao afirmar que 'tende a ser de famílias mais ricas', pois há farto material bibliográfico que consegue deixar esta informação precisa (AMARAL, 2017, p. 19, grifos do autor).
\end{abstract}

Tal argumento sustenta a recomendação de que as Instituições Federais de Educação Superior - Ifes cobrem mensalidades de quem pode pagar, abrindo mão do princípio de gratuidade da universidade pública.

Amaral (2017), professor da Universidade Federal de Goiás, em artigo produzido para subsidiar o debate no âmbito das Ifes e da Associação Nacional dos Dirigentes de Instituições Federais de Educação Superior - Andifes -, rebate o relatório do Banco Mundial no que considera "mitos" em torno da universidade púbica brasileira, sobretudo pelas inconsistências nos dados e fragilidades argumentativas.

Em relação às políticas para a formação de professores, no mês de outubro de 2017, foi lançada oficialmente a política do governo. As mudanças partiram de um diagnóstico ${ }^{2}$ que apontou: desempenho insuficiente dos estudantes, baixa qualidade da formação inicial dos professores no país, histórico de currículos extensos com ausência de atividades práticas e estágios curriculares sem planejamento e sem vinculação com as escolas. A nova política consiste em:

\footnotetext{
${ }^{2}$ Não há informações quanto às fontes do diagnóstico.
} 
- criação da Residência Pedagógica em substituição ao Programa Institucional de Bolsas de Iniciação à Docência - Pibid;

- ampliação das vagas da Universidade Aberta do Brasil - UAB - para primeira e/ou segunda licenciatura ( $75 \%$ das vagas);

- investimento em mestrado profissionalizante e especialização para professores de educação básica, abrangendo todas as áreas e componentes curriculares da Base Nacional Comum Curricular - BNCC;

- alteração do Programa Nacional de Alfabetização na Idade Certa - Pnaic -, com a redução de bolsas e introdução do programa de tempo integral;

- flexibilização do Prouni, aumentando a oportunidade de ingresso em instituições privadas;

- processo seletivo específico para professores de educação básica nas Ifes;

- Programa de Formação Inicial e Continuada para Professores - Profic - em substituição ao Plano Nacional de Formação de Professores - Parfor.

Em relação à Residência Pedagógica, que substitui o Pibid, há muitas dúvidas, visto que a própria Capes $^{3}$ manifesta estar em processo de formulação do programa. O que se sabe é que ocorrerá ao longo do curso de Licenciatura, a partir do $3^{\circ}$ ano, na modalidade de estágio supervisionado. Isto é, haverá alteração na modalidade de estágio, além da redução do número de bolsas, notadamente para professores supervisores da universidade e da escola de educação básica, na medida em que será considerado um componente curricular obrigatório.

A ampliação das vagas da UAB em cursos de Licenciatur, embora apresente aspectos positivos, pois busca atender às regiões mais distantes e de difícil acesso do país, onde se encontra o maior número de escolas com professores sem formação adequada, também apresenta dificuldades de efetivação. Isso porque as despesas com a sua manutenção nem sempre são cobertas em tempo pela Capes, órgão responsável pela gestão. Não raro, as IES assumem os encargos com a elaboração dos materiais, manutenção dos laboratórios e estúdios, deslocamentos de professores para os polos, entre outros, aguardando o repasse dos recursos por parte do governo.

Quanto ao Mestrado Profissional, o que se destaca é a ênfase que deve ser dada para a questão dos conteúdos presentes na Base Nacional Comum Curricular, o que se pode inferir que o modelo de formação está orientado para potencializar o professor como um prático de aula, mesmo em nível de pós-graduação.

O Pacto Nacional pela Alfabetização na Idade Certa - Pnaic/MEC - sofreu mudanças em 2017, passando a

\footnotetext{
3 Coordenação de Aperfeiçoamento de Pessoal de Nível Superior.
}

incorporar ,além da formação em Língua Portuguesa e Matemática para os anos iniciais do ensino fundamental e da educação infantil, o Novo Mais Educação, que se refere à educação em tempo integral. Na perspectiva do Pnaic anterior, o ciclo de alfabetização era de três anos, sendo concluído aos oito anos de idade. A partir da aprovação da nova BNCC para o ensino fundamental, a criança deve ser alfabetizada até os sete anos de idade, no $2 \underline{ }$ ano do ensino fundamental, rompendo com o tempo até então construído teoricamente como sendo o adequado para completar o processo de letramento.

É possível perceber a centralidade das políticas para a formação de professores nos conteúdos e, notadamente, nas áreas de Português e Matemática, além da Educação Infantil. O Programa de Formação Inicial e Continuada de Professores - Profic/Capes - apresenta a mesma centralidade ao definir as áreas prioritárias (Educação Infantil, Alfabetização, Português e Matemática) para professores que já atuam em sala de aula.

A influência dos organismos internacionais, especialmente do Banco Mundial, na elaboração das políticas para a educação no país e, portanto, a "governança transnacional", pode ser evidenciada pela quantidade e pelo conteúdo dos documentos produzidos. Ao analisar o documento "Aprendizagem para todos: estratégia de educação 2020 do Grupo Banco Mundial/2011”, voltado para os países em desenvolvimento, foi possível perceber a focalização das políticas curriculares na questão da "aprendizagem para todos"4. O que significa, segundo o documento, que todas as crianças e jovens adquiram conhecimentos e habilidades de que necessitam para terem uma vida saudável, produtiva e para obterem um emprego significativo. Apresenta como pilares da estratégia: investir antecipadamente, investir de forma inteligente, investir para todos (CÓSSIO, 2015).

Depreende-se que investir antecipadamente seria inserir as crianças mais cedo na escola (educação infantil)

\footnotetext{
4 No sumário, o documento referido deixa explícita a sua intencionalidade:

O Grupo Banco Mundial está empenhado em consolidar esse progresso e a incrementar o seu apoio para ajudar todos os países a alcançarem a Educação para Todos (EFA) e os objectivos de educação das Metas de Desenvolvimento do Milénio (MDG). O motor deste desenvolvimento no entanto será, em última análise, o que as pessoas aprendem, dentro e fora da escola, desde o jardimescola até ao mercado de trabalho. A nova estratégia do Banco para 10 anos procura alcançar este objectivo alargado de "Aprendizagem para Todos", promovendo reformas nos sistemas de educação dos países e criando uma base global de conhecimento suficientemente forte para liderar estas reformas (2011, p. 1).

Destaca-se a permanência da proposta de Education For All-EFA-, pois está presente desde 1990, desencadeada pela Conferência Mundial de Educação para Todos, em Joimtien, na qual o BM foi um dos promotores, ao lado de outros organismos como Unesco, Unicef e Pnud. Embora se saiba que a EFA tenha sido coordenada pela Unesco, foi aos poucos sendo apropriada pelo banco, em consequência das mudanças de agenda que vem sofrendo desde a sua criação.
} 
e focar os anos iniciais do ensino fundamental, o que está em sintonia com as políticas atuais para a formação de professores. Investir de forma inteligente não significa investir mais, mas fazer mais com o mesmo, ou seja, implica gestão (gerencial) das instituições públicas por meio de base de dados e controle de resultados, o que, pelo discurso corrente, resultaria em qualidade. Por fim, investir para todos poderia ser traduzido pelo currículo único, que sob o discurso do "direito à aprendizagem" elege algumas competências como sendo as necessárias e básicas para serem aprendidas e medidas posteriormente pelas avaliações nacionais.

A definição de uma Base Nacional Comum Curricular não se refere somente à educação básica. Para consolidá-la, está em processo de elaboração pelo Ministério da Educação - MEC - a Base Curricular para a Formação de Professores, o que irá impactar sobremaneira a organização dos projetos pedagógicos dos cursos de Licenciatura. E talvez possa colocar em risco a materialização da Resolução n. 02/2015/CNE, que define as Diretrizes Curriculares Nacionais para a formação de professores, na medida em que será outra proposta curricular.

\section{CONSIDERAÇÕES FINAIS}

Busca-se neste artigo destacar os conceitos de Nova Gestão Pública (NGP) e de governança por acreditar que são importantes para compreender as transformações no papel e nas funções do Estado, em diferentes escalas. Como também são relevantes, sobretudo, a relação entre o público e o privado e as implicações para as políticas educacionais e para a formação de professores, além da relação do Estado com os organismos internacionais, encaminhando para a noção de governança transnacional.

Esta, como referido, diz respeito ao fortalecimento dos instrumentos de regulamentação transnacionais e caracteriza-se pelo aumento do uso de mecanismos de monitoramento e ações de auditoria, baseados em evidências, como é o caso das políticas de avaliação em larga escala e dos indicadores educacionais.

É transnacional porque ultrapassa as fronteiras nacionais, e não é global, pois não se trata de acordos entre nações, mas de arranjos, projetos e políticas, sob a coordenação de organismos multilaterais, como o Banco Mundial e OCDE.

Reis (2013) conclui:

Governança pode traduzir-se pelo modo de coordenação dos diferentes tipos de arranjos institucionais presentes num dado sistema social de produção, Mercados, Hierarquias, Estado, Redes, Associações e Comunidades, cujas ordens relacionais, diversas e parciais, configuram uma dada forma institucional dominante ou prevalecente.

Dessa forma, a good governance proposta pelo Banco Mundial é entendida como um novo processo de governar em que os Estados nacionais atuam como reguladores e não como atores. O que significa que outros atores entram em cena: mercado e sociedade civil, atuando em áreas estratégicas que antes eram exclusivas do Estado, como é o caso da educação. Esse papel de regulador atribuído ao Estado, implica desenvolver mecanismos cada vez mais sofisticados de controle a distância.

Nesse sentido, relacionam-se algumas políticas recentemente anunciadas pelo governo para a formação de professores, como parte da reforma mais ampla da educação brasileira, com o contexto macro. Destaca-se ainda o papel do Banco Mundial nesse cenário, por ser o mais importante indutor de políticas educacionais para os países em desenvolvimento.

O conjunto de políticas educacionais lançado recentemente para a formação inicial e continuada de professores traduz a concepção de docente, almejada, notadamente com ênfase na prática de sala de aula. A perspectiva é a do professor como um solucionador de problemas cotidianos e conhecedor dos conteúdos previstos na BNCC, assim como das maneiras de transmiti-los. Assim sendo, os alunos, com prioridade para as crianças da pré-escola e dos anos iniciais do ensino fundamental, são devidamente alfabetizados em Português e Matemática. O que possibilita, dessa forma, que os pequenos estudantes possam ser no futuro jovens e adultos produtivos.

Para Ball (2014), "as tecnologias neoliberais trabalham em nós para produzir um corpo docente e discente 'dócil e produtivo', e professores e alunos responsáveis e empreendedores" (p. 64).

Entende-se que o empresariamento da educação, através da participação ativa dos setores de mercado, seja uma forma de privatizar a educação pública, incidindo sobre seus fins e objetivos, ressignificando e/ou modificando princípios que foram considerados essenciais para a formação plena de pessoas para a cidadania e para a democracia, inseridos na Constituição Federal de 1988 e nas legislações educacionais. O que pode se manifestar tanto na forma de entidades, grupos, redes atuando diretamente na oferta de serviços e produtos educacionais quanto na forma de gerir o setor público como se fosse um ente privado, ou, ainda, através de políticas educacionais que reduzem a formação docente à prática, baseada em conteúdos estandardizados. Assim, o slogan dos empresários, assumido pelo governo brasileiro, "todos pela educação", alcança o consenso, só que não foi dito que era "todos pela educação para o mercado". 


\section{REFERÊNCIAS}

AMARAL, Nelson Cardoso. A hora da verdade para as universidades federais brasileiras: metas do PNE (20142024) e 10 mitos a serem debatidos e desvendados, 2017.

BALL, Stephen. Diretrizes políticas globais e relações políticas locais em educação. Currículo sem Fronteiras, v. 1, n. 2, p. 99-116, jul./dez. 2001.

BALL, Stephen. Profissionalismo, gerencialismo e performatividade. Cadernos de Pesquisa, v. 35, n. 126, p. 539-564, set./dez. 2005.

BALL, Stephen. Educação global S.A.: novas redes políticas e o imaginário neoliberal. Ponta Grossa: Uepg, 2014.

BANCO MUNDIAL. Estratégia 2020 para a educação do Grupo Banco Mundial. Resumo executivo. Aprendizagem para todos: investir nos conhecimentos e competências das pessoas para promover o desenvolvimento. Washington, DC: Banco Mundial, 2011.

BANCO MUNDIAL. Um ajuste justo: análise da eficiência e equidade do gasto público no Brasil. Banco Mundial, 2017.

CARNEIRO, Ricardo; MENICUCCI, Telma Maria. Gestão pública no século XXI: as reformas pendentes. In: A saúde no Brasil em 2030: prospecção estratégica do sistema de saúde brasileiro: desenvolvimento, Estado e políticas de saúde, v. 1. Rio de Janeiro: Fiocruz/Ipea/Ministério da Saúde, 2013.

CÓSSIO, Maria de Fátima. Base Nacional Comum: uma discussão para além do currículo. In: Revista e-Curriculum, São Paulo, v. 12, n. 3, p. 1570-1590, out./dez. 2014.

CÓSSIO, Maria de Fátima. Agenda transnacional e governança nacional: as possíveis implicações na formação e no trabalho docente. In: Revista e-Curriculum, São Paulo, 2015.

DASSO JÚNIOR, Aragon. Em busca de um modelo alternativo de administração pública: críticas à hegemonia do gerencialismo. Anais I ENEPCP - Encontro Nacional de Ensino e Pesquisa do Campo de Públicas. Brasília/DF, 2015. p. 1-15.
FREITAS, Luiz Carlos. Qualidade negociada: avaliação e contra-regulação na escola pública. Educação e Sociedade, v. 26, n. 92 , 2005, p. 911-933.

HOOD, Christopher. Racionalismo económico en la gestión pública ¿De la administración pública progresiva a la nueva administración pública? In: Lecturas en Gestión Pública. Madrid: Ministerio de Administraciones Públicas, 1996. p. 447-467.

MAROY, Christian. Em direção a uma regulação pós-burocrática dos sistemas de ensino na Europa? In: OLIVEIRA, Dalila Andrade; DUARTE, Adriana. Políticas públicas e educação: regulação e conhecimento. Belo Horizonte: Fino Traço, 2011.

OLIVEIRA, Dalila Andrade. As políticas públicas em educação e a pesquisa acadêmica. In: OLIVEIRA, Dalila Andrade; DUARTE, Adriana (Orgs.). Políticas públicas e educação: regulação e conhecimento. Belo Horizonte: Fino Traço, 2011.

PERONI, Vera. Diálogos sobre as redefinições no papel do Estado e nas fronteiras entre o público e o privado. São Leopoldo: Oikos, 2015.

REIS, Isaura. Governança e regulação da educação: perspectiva e conceitos. In: Educação, Sociedade e Culturas, n. 39, 2013 .

ROBERTSON, Susan. As implicações em justiça social da privatização nos modelos de governança da educação: um relato relacional. Educação e Sociedade, v. 34, n. 34, jul.-set. 2013.

SECCHI, Leonardo. Modelos organizacionais e reformas da administração pública. In: Rev. Adm. Púb, Rio de Janeiro, v. 43, n. 2, mar./abr. 2009.

SHIROMA, Eneida Oto. Redes de políticas públicas e governança da educação: pesquisando a convergência das políticas para docentes nas agendas para a próxima década. Relatório de Pesquisa, Florianópolis: UFSC, 2016.

Recebido em 22-12-2017

Aprovado em 19-03-2018. 